\title{
Annotation
}

\section{Dilated cardiomyopathy}

Dilated cardiomyopathy is characterised by the echocardiographic appearance of dilatation of the left or both ventricular cavities with reduced contractility. It is the principal reason for children to present to paediatricians with cardiac failure after infancy and is the most common indication for cardiac transplantation in paediatric practice. ${ }^{12}$

\section{Cardiac investigations}

Typically, the child will have symptomatic cardiac failure and chest radiography demonstrates cardiomegaly. The diagnosis is established with echocardiography. Increasingly, the diagnosis is made at the referring hospital. It is prudent to refer to a tertiary centre to exclude congenital heart disease, particularly anomalous origin of the left coronary artery from the pulmonary artery, although this can usually be inferred from ischaemic changes on the electrocardiogram. The electrocardiogram in dilated cardiomyopathy may show broadening of the QRS complexes and there may be evidence of left ventricular strain with some $\mathrm{T}$ wave changes. The left ventricular voltages are often increased. If they are markedly increased, the diagnosis of endocardial fibroelastosis is considered, although this may not be a distinct entity. ${ }^{3}$ A 24 hour electrocardiogram is helpful to exclude periods of secondary arrhythmias such as ventricular tachycardia and atrial flutter, as the documentation may be useful in defining prognosis. It is also worth ensuring that there is not an incessant tachycardia which may have been the primary cause of the cardiomyopathy. In these cases the heart rate is inappropriately fast with little variation and typically the $P$ waves have an unusual axis and morphology.

Echocardiographic screening of family members is indicated as it is increasingly recognised that dilated cardiomyopathy is familial in some cases, ${ }^{4}$ but the inheritance and molecular genetics are not clear. Most cases are probably dominant with variable penetrance but recessive and $\mathrm{X}$ linked inheritance have been described, the latter having been mapped to the dystrophin gene and to $X_{q}$ 28: so called $\mathrm{X}$ linked cardiomyopathy and Barth's syndrome respectively. ${ }^{56}$ Family screening should be handled sensitively and probably is not indicated during the initial phase of investigations.

Cardiac catheterisation and angiography are rarely required, even before transplantation, although there may be a role for angiography in the exclusion of an anomalous coronary artery if echocardiographic pictures are unsatisfactory.

\section{Search for secondary causes of dilated} cardiomyopathy

Many paediatricians have been faced with a daunting list of investigations for children with dilated cardiomyopathy. Unfortunately the yield is dishearteningly low. In adults approximately half of all cases, but in children the majority, are idiopathic. Despite this, it remains wise to exclude metabolic, endocrine, storage, mitochondrial, and connective tissue disease in a systematic way, as in hypertrophic cardiomyopathy in children. ${ }^{7}$ This will involve taking urine for amino acids and organic acids, and blood for fasting lactate and glucose, iron and iron binding capacity, amino acids, creatine kinase $\mathrm{MM}$ (raised in X linked cardiomyopathy), vacuolated lymphocytes, carnitine, thyroid function, and an autoimmune screen. Other causes can be excluded from history and examination, for example anthracycline toxicity, haemochromatosis, neuromuscular disorders, and nutritional deficiency. A history of intermittent neutropenia suggests Barth's syndrome, or methylglutaconic aciduria. ${ }^{8}$ Primary carnitine deficiency is associated with a progressive cardiomyopathy, which is usually a dilated cardiomyopathy, although in some cases may be hypertrophic ${ }^{9}$ but typically the contractility is reduced. Low plasma carnitine and acylcarnitine concentrations are found (that is low free and total carnitine). A 'secondary' deficiency of carnitine may be found in other inborn errors and there may be an associated cardiomyopathy. In these cases, carnitine is utilised in esterification of acyl-CoA to acylcarnitine with high plasma and urine concentrations of the latter. The cardiomyopathies of primary carnitine deficiency often respond dramatically to replacement treatment, but those of secondary deficiencies may not. ${ }^{10}$

\section{Myocarditis}

One of the dilemmas for paediatricians faced with a new case of dilated cardiomyopathy is the possibility that it could be myocarditis. Firstly, this is a problem because some have advocated immunosuppression as a treatment for myocarditis, ${ }^{11}$ however, a recent study in adults failed to demonstrate any role for immunosuppression. ${ }^{12}$ The second and probably more relevant area of concern is that myocarditis patients may improve spontaneously when the precipitating cause is removed and therefore any decision to refer a new patient for cardiac transplantation should be deferred until myocarditis has been completely excluded. Unfortunately it is very difficult to diagnose myocarditis. A history of a recent viral illness is very common in paediatric practice. A rising titre on paired serology, or positive viral cultures are helpful, but will not enable an early diagnosis to be made. Viruses often implicated in myocarditis are: coxsackie, echo, influenza, parainfluenza, HIV, mumps, rubella and rubeola, although other viral and nonviral (bacterial, fungal, protozoal, rickettsial, and spirochaetal) causes have been described. A myocardial biopsy is considered to be a gold standard, but inflammatory changes may not be present throughout the ventricle and therefore normal areas of myocardium may be biopsied. In 
addition, interpretation of the biopsy is subjective and the procedure itself is not without risk in a sick child. Further confusing the issue is the evidence that cases of dilated cardiomyopathy may also improve ${ }^{1314}$ and myocarditis may possibly develop into dilated cardiomyopathy. ${ }^{15}$ Therefore, it is probably wise to consider and manage patients with possible myocarditis similarly to those with dilated cardiomyopathy in terms of decision strategy.

\section{Management}

Angiotensin converting enzyme inhibitors are the principal group of drugs that prolong survival in adults with left ventricular dysfunction, ${ }^{16}$ and in paediatric practice too they have become the mainstay of treatment. Care is taken to avoid hypotension (particularly in children already on diuretics who may therefore have a high renin) by starting at a low dose. Diuretics are helpful in improving symptoms of congestive heart failure. Initially fluids may need to be restricted particularly if there is hyponatraemia, which should not be treated with extra salt. The role of digoxin as an oral inotrope remains unclear. $\beta$ Blockers have been used in adults with dilated cardiomyopathy, ${ }^{17}$ and may improve cardiac function, but they have not been widely used in children with the disease. Intravenous inotropes and vasodilators are occasionally needed. Anticoagulation is advisable to prevent the catastrophic sequelae of embolisation from intracavity thrombus. ${ }^{18}$ Often heparin or warfarin are used, but in improving or stable patients it may be possible to use aspirin alone. Arrhythmias need to be treated if they are causing symptoms, or are felt to be the principal cause of the cardiomyopathy, but as most antiarrhythmic agents (apart from digoxin) are negative inotropes it is wise to exercise caution. It is uncertain whether asymptomatic arrhythmias documented on monitoring should be treated.

\section{Prognosis}

The actuarial survival of dilated cardiomyopathy in children is around $60 \%$ at 5 years, but the outcome appears better in younger children. ${ }^{13}$ In general, one can determine three groups of patients. Firstly, those in whom cardiac function returns to normal (this usually occurs within three months of presentation); these patients have a good prognosis and do not appear to be at continued risk of sudden death. Secondly, those that show improvement in systolic function, but it does not return to normal. This group remain at risk of sudden death. Thirdly, those whose cardiac function shows no improvement or deterioration in systolic function. This group are at high risk of early death from profound cardiac failure. Other signs of poor prognosis are the presence of mural thrombus and ventricular arrhythmias.

\section{Cardiac transplantation}

Dilated cardiomyopathy is the commonest reason for cardiac transplantation in children. ${ }^{2}$ (In infants congenital heart disease is a more common indication, but more transplants are performed after the age of 5 years and in this age group $>60 \%$ are for dilated cardiomyopathy.) The outcome of transplantation in this condition is better than the outcome for other reasons such as congenital heart disease with an actuarial survival of $85 \%$ at 3 years. ${ }^{1}$ The medium and long term future after cardiac transplantation is uncertain and therefore patient selection is very important. Compounding this is the possibility that the child with dilated cardiomyopathy may improve spontaneously. ${ }^{13}$ In general, transplantation should be reserved for those children whose cardiac function continues to deteriorate despite maximal medical treatment. Unfortunately, the decision must be made early as over half of the deaths from cardiac failure occur within three months of presentation and many die awaiting a suitable donor heart.

\section{Artificial heart}

A mechanical bridge to transplant was first described almost 20 years ago, ${ }^{19}$ and devices designed for long term support have been successfully implanted in the UK (S Westaby, personal communication, Oxford). Unfortunately, these devices are too large to be inserted in patients $<1.5 \mathrm{~m}^{2}$ body surface area, which precludes their use in many adults and all children. Recent ovine trials of an axial flow pump in the USA, ${ }^{20}$ and recently in Oxford, have been encouraging. It is likely that such a device will be implanted in a child before the millennium and ultimately could become an alternative to transplantation.

\section{Conclusions}

Dilated cardiomyopathy is an uncommon disorder in children, but it accounts for a disproportionate number of deaths in paediatric cardiology practice. The prognosis is probably better in those presenting under 2 years of age and/or if there is clear evidence of echocardiographic improvement. Transplantation offers hope to patients not responding to medical therapy, but the timing of transplantation remains a difficult clinical decision for those involved in the care of these children.

MICHAEL BURCH MARTIN RUNCIMAN

Paediatric Cardiology

Fohn Radcliffe Hospital,

Headington,

Oxford OX3 $9 D U$

1 Adwani SS, Whitehead BF, Rees PG, et al. Heart transplantation for dilated cardiomyopathy. Arch Dis Child 1995; 73: 447-52.

2 Hosenpud JD, Novick RJ, Breen TJ, Keck BS, Daily P. The registry of the International Society for Heart and Lung Transplantation: 12th official report 1995. F Heart Lung Transplant 1995; 14: 805-15.

3 Lurie P. Endocardial fibrelastosis is not a disease. Am $f$ Cardiol 1988; 62: 468-70.

4 Michels VV, Moll PP, Miller FA, et al. The frequency of familial dilated cardiomyopathy in a series of patients with idiopathic dilated cardiomyopathy. N Engl f Med 1992; 326: 77-82.

5 Towbin JA, Hejtmancick JF, Brink P, et al. X linked cardiomyopathy: molecular genetic evidence of linkage to the Duchenne muscular dystrophy (dystrophin) gene at the $\mathrm{X}_{\mathrm{p}} 21$ locus. Circulation 1993; 87:185465.

6 Bolhuis PA, Hensels GW, Hulsebos TJM, Baas F, Barth PG. Mapping of the locus for X linked cardioskeletal myopathy with neutropenia and abnormal mitochondria (Barth syndrome) to $\mathrm{X}_{\mathrm{q}} 28$. Am f Hum Genet 1991; 48: mitoch.

7 Burch M. Hypertrophic cardiomyopathy. Arch Dis Child 1994; 71 : 488-9.

8 Ostman-Smith I, Brown G, Johnson A, Land JM. Dilated cardiomyopathy due to type II X-linked 3-methylglutaconic aciduria: successful treatment due to type II X-linked 3-methylglutaconic aciduria:

9 Ino T, Sherwood WG, Benson LN, Wilson GJ, Freedom RM, Rowe RD. Cardiac manifestations in disorders of fat and carnitine metabolism in infancy. $\mathcal{F}$ Am Coll Cardiol 1988; 11: 1301-8.

10 Massoud AF, Leonard JV. Cardiomyopathy in propionic acidaemia. Eur Pediatr 1993; 52: 441-5.

11 Chan KY, Iwahara M, Benson L, Wilson GJ, Freedom RM. Immunosuppressive therapy in the management of acute myocarditis in children: a clinical trial. $\mathcal{F}$ Am Coll Cardiol 1991; 17: 458-60.

12 Mason JW O'Connell JB, Herskowitz A, et al. A clinical trial of immunosuppressive therapy for myocarditis. $N$ Engl f Med 1995; 333: 269-75.

13 Burch M, Siddiqi SA, Celermajer DS, Scott C, Bull C, Deanfield JE. Dilated cardiomyopathy in children: determinants of outcome. Br Heart $\mathcal{f} 1994$; 72: $246-50$.

14 Steimle AE, Stevenson LW, Fonaron GC, Hamilton MA, Moriguchi JD. Prediction of improvement in recent onset cardiomyopathy after referral for heart transplantation. $\mathcal{F} \mathrm{Am}$ Coll Cardiol 1994; 23: 553-9. 
15 Bowles NE, Richardson PJ, Olsen EG, Archard LC. Detection of coxsackie $B$ virus specific RNA sequences in myocardial biopsy samples from patients with myocarditis and dilated cardiomyopathy. Lancet 1986; i $1120-3$.

16 The SOLVD investigations. Effect of enalapril on mortality and the development of heart failure in asymptomatic patients with reduced left ventricular ejection fractions. N Engl $\mathcal{f}$ Med 1992; 327: 685-91 17 Waagstein F, Bristow MR, Sueedburg K, et al. Beneficial effect of metoprolol in idiopathic dilated cardiomyopathy. Metoprolol in dila
cardiomyopathy (MDC) trial study group. Lancet 1993; 342: 1441-6.
18 Gottdiener JS, Gray JA, VanVoorhees L, DiBianco R, Fletcher RD Frequency and embolic potential of left ventricular thrombus in dilated cardiomyopathy: assessment by 2 dimensional echocardiography. $\mathrm{Am} \mathcal{f}$ Cardiol 1983; 52: 1281-5.

19 Reemtsma K, Drusin R, Edie R, Bregman D, Dobelle W, Hardy M. Cardiac transplantation for patients requiring mechanical circulatory support. $N$ Engl $\ngtr$ Med 1978; 298: 670-1.

20 Kaplon RJ, Oz MC, Kwiatkowski PA, et al. Miniature axial flow pump for ventricular assistance in children and small adults. $\begin{aligned} & \text { J Thorac Cardiovasc Surg } \\ & \text { S }\end{aligned}$ ventricular assista 